\title{
Research on power control strategy of household-level electric power router based on hybrid energy storage droop control
}

\author{
Kun Huang ${ }^{1,2}$, Yanman Li ${ }^{1,2}$, Xiaoyan Zhang ${ }^{1,2}$, Lei Liu ${ }^{3}$, Yanbin Zhu ${ }^{4^{*}}$ and Xin Meng ${ }^{4}$
}

\begin{abstract}
In the light of user-side energy power control requirements, a power control strategy for a household-level EPR based on HES droop control is proposed, focusing on the on-grid, off-grid and seamless switching process. The system operating states are divided based on the DC bus voltage information with one converter used as a slack terminal to stabilize the DC bus voltage and the other converters as power terminals. In the on-grid mode, the GCC and the HES are used as the main control unit to achieve on-grid stable operation, whereas in the off-grid mode, the PV, HES and LC are used as the main control unit at different voltages to achieve stable operation of the island network. Finally, a DC MG system based on a household-level EPR is developed using the PSCAD / EMTDC simulation platform and the results show that the control strategy can effectively adjust the output of each subunit and maintain the stability of the DC bus voltage.
\end{abstract}

Keywords: Household-level electric power router, Hybrid energy storage, Droop control, On-grid mode, Off-grid mode

\section{Introduction}

The existing large power grid will remain the main part of the future energy Internet $[5,26]$. Despite the diverse forms of energy, electrical energy has great advantages in terms of transmission efficiency and economy. Electrical energy can also be easily converted to other forms (cold or hot) of energy. Therefore, the EPR as an energy conversion device has received increasing attention in industry and academia [22].

At present, the traditional distribution network is facing diverse problems and challenges. The fragility of the distribution network structure does not provide sufficient support to the access of a large amount of renewable energy, while the problems of poor node autonomy

\footnotetext{
* Correspondence: zhuyanbin@tju.edu.cn

${ }^{4}$ Key Laboratory of Smart Grid of Ministry of Education, Tianjin University, Tianjin 300072, China

Full list of author information is available at the end of the article
}

and low degree of freedom are becoming more serious [42]. In addition, distributed generations have the characteristics of high uncertainty, high uncontrollability, wide distribution, remote location, harsh operating environment, low equipment reliability, and large operational and maintenance workload [27]. The power system is also developing towards a new stage of coordinated and optimized "source-network-load-storage" operation, which will become the core of the future energy internet $[1,6]$. In the future, the power system will be formed by bottom-up autonomous units of electrical energy through peer-to-peer interconnection. Such open, interconnected, peer-to-peer and shared power systems require a high degree of integration of information and electrical energy, and precise, continuous, fast, and flexible control methods. The traditional grid-connected distributed power generation devices cannot realize the scheduling and independent management of the user's 
electric energy, while the user side lacks equipment for implementing electric energy management and control. With this as background, the concept of "electric power router" based on power electronics technology has come to the fore [7].

As a key device of the energy Internet, current research on the power router is mainly focused on electrical topology and control strategy. In terms of electrical topology, references $[8,23,43]$ propose a three-port DC converter with simple structure, flexible control, and easy implementation. However, its expansion is limited. In [39], a four-port converter with three input ports and one output port is proposed for application in the new energy power generation. It has high switch utilization, simple topology and high energy density, but the number of ports is limited and energy cannot flow in both directions. Four-port and three-port DC-DC converters with multi-winding high-frequency isolation transformers and high power density are proposed in $[19,30]$, respectively. The output of multiple voltage levels is realized through a multi-winding transformer. However, such converters require complicated parameter adjustment and have high production cost. Reference [28] describes a large-capacity MPC topology with an AC or DC bus, in which each port is connected with an $\mathrm{AC}$ or DC bus and bidirectional flow of energy can be realized.

The electric power router has evolved from the structure of a power electronic transformer, while its development process has gone through several stages of high-frequency transformer, fully electronic transformer, intelligent high-frequency transformer, high-voltage high-frequency transformer, and multi-port routing transformer. At present, an electric power router can implement intelligent management and control of distributed power generation equipment, energy storage and the existing power network, and realize an electrical energy dispatch control function.

The power router based on the multi-port routing transformer structure is generally used in small and medium power applications, and is suitable for power conversion and control between low-voltage power distribution system on the user side and household distributed power supply. The electrical topology of the existing power routers is largely mature, but research on the control strategy is urgently needed. This paper adopts a multi-port routing and transformer power router topology, which not only achieves the basic requirements such as voltage conversion, reliable electrical isolation, independent port design, and two-way energy flow, but also reduces equipment costs, improves efficiency, reduces size, and expands the flexibility of port use $[9,20,24,46]$.
A lot of research has been carried out on the power control strategy of an EPR. In [21], a coordinated control strategy based on a DC bus voltage signal is used, while the operation target and power distribution of the system are realized by using the cooperation of threshold voltage and droop control. In [25], the DC bus voltage is used to distinguish between on-grid and off-grid modes of operation, and the DC$\mathrm{AC}$ converter and energy storage unit connected to the grid are used to maintain the bus voltage. However, in the on-grid mode, the energy storage unit is always in a standby state with low utilization rate. In $[14,34]$, the droop control strategy is used to ensure a smooth transition of the DC bus voltage between different levels. However, since the working curve of each unit in the DC MG has to be predetermined, the flexibility of the system is low.

Most existing literature discusses the operation and control of a DC MG in island mode. Because of the lack of backup, when energy surplus or shortage occurs, system stability is poor and the application is limited. Studies on the operating status under direct grid connection are usually under the support of a large power grid, so the coordinated control of PV and other micro power sources and energy storage is ignored, and the influence of factors for energy storage batteries such as remaining capacity cannot be fully considered, causing battery damage and harm.

In summary, although the current technical specifications of the electrical energy router standard have not been uniformly formulated [10, 17, 29, 32, 37], a lot of work has been done on topology optimization and key technology analysis. This paper comprehensively considers the operating characteristics of the off-grid operation mode and integrates the converter control strategies into a household-level electric power router. Taking home user applications as the main operating scenario, two on-grid and 6 off-grid operating modes are designed. Various application scenarios are proposed, and the proposed control strategy ensures that the system can smoothly switch between the various working modes, and realize stable and reliable operation of the user system and the efficient use of energy.

The organization of the rest of the paper is as follows. The topology of a household-level electrical energy routing device is introduced in Section II and according to the system DC bus voltage information, the corresponding system power control strategy is proposed in Section III. In Section IV, a system model containing PV, hybrid energy storage, gridconnected converters, AC and DC loads is developed on the PSCAD / EMTDC simulation platform to verify the effectiveness of the proposed control strategy. Finally, Section V draws the conclusions. 


\section{Household-level electric power router}

\subsection{Topology of the household-level electric power router} The basic architecture of the household-level EPR is shown in Fig. 1. As the "electric energy housekeeper" of home users, the household-level EPR is connected to the grid, PV, HES, AC loads and DC loads, and a representative application scenario is shown in Fig. 2.

The AC and DC loads mainly include heating, lighting, and other cold and hot electrical equipment. These loads operate normally when the system has sufficient electrical energy supply, but can be adjusted by an LC for reduced power operation when the system energy supply is insufficient.

\subsection{Photovoltaic}

The output $I-V$ and $P-V$ characteristics of the PV matrix are non-linear, resulting in a maximum power point which is determined by the light intensity and the ambient temperature $[31,38,40]$. Considering the intermittency and fluctuation of light, the MPPT algorithm is adopted to enable the PV to generate the maximum power to meet the load demand and improve the system conversion rate.

The MPPT algorithm mainly includes the disturbance observation, conductance increase, and power feedback methods [13]. Among them, the disturbance observation method is widely used because of its simple algorithm and easy implementation, independent of the electrical parameters of the PV array, and high tracking efficiency $[3,11,12,33]$. In this paper, an improved variable step size disturbance observation method is used, and its algorithm program is shown in Fig. 3. As seen, the method measures the output voltage and current of the PV cell, and then calculates the output power. By comparing the absolute difference between the voltage amplitudes at the previous and current sampling, it makes a judgement on whether the PV cell is operating at the maximum power point. If not, a new value will be assigned to the

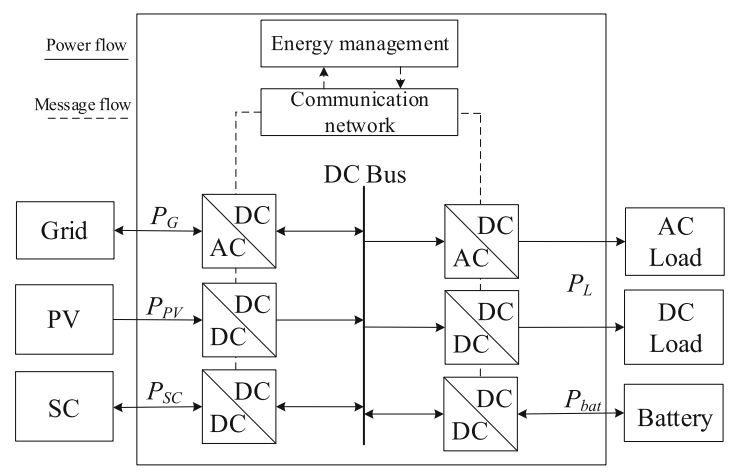

Fig. 1 Basic architecture of household-level electric power router

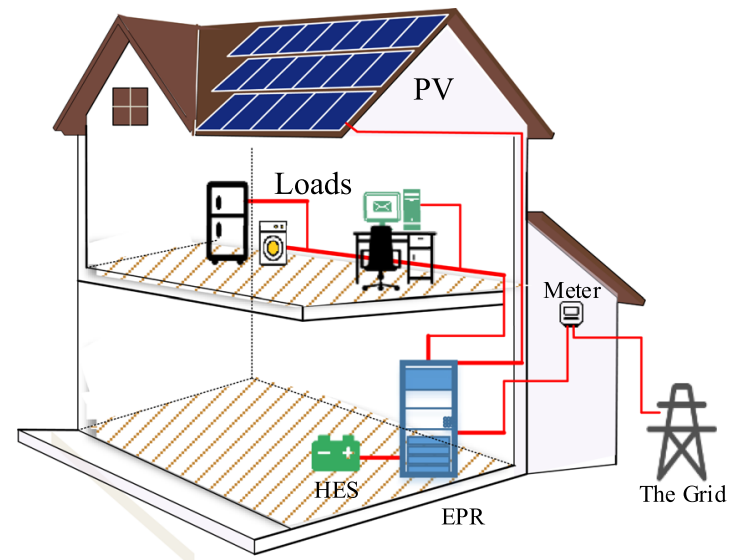

Fig. 2 Application scenarios of a household-level electric power router

reference voltage according to the formula given by step size.

\subsection{Hybrid energy storage}

Renewable energy sources have inherent characteristics such intermittency and variation, making it difficult for them to provide continuous and stable electrical energy. Therefore, when the MG system operates in off-grid mode, the energy storage unit is key to ensuring the stable operation of the system. However, it is difficult for any energy storage technology to consider all aspects such as safety and reliability, high power/energy density, high efficiency, long life, and low cost. Therefore, this

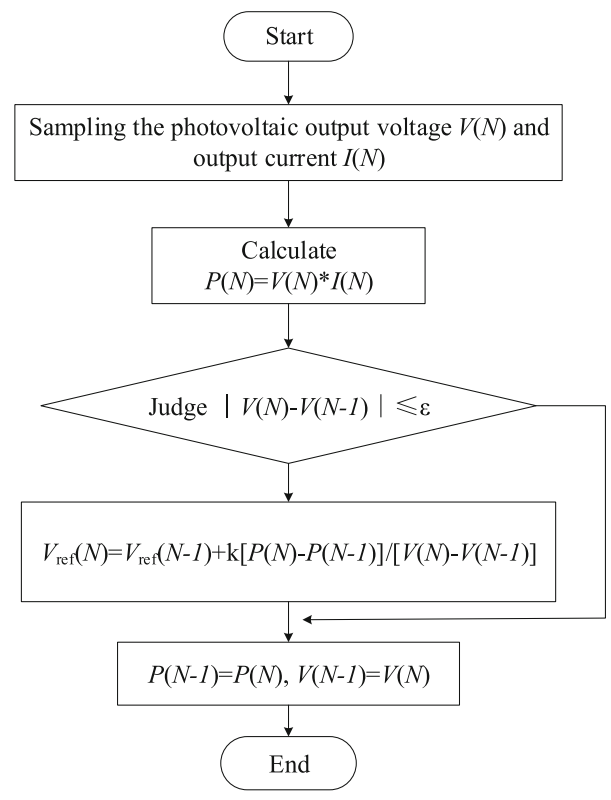

Fig. 3 The principle of the improved variable step size disturbance observation method algorithm 
paper uses a hybrid energy storage form of lithium battery and super capacitor to benefit from the advantages of the different energy storage technologies to meet the needs of power and energy. This is the development and application trend of distributed energy storage technologies [41].

Lithium battery energy storage is an energy-type energy storage with high energy density, but low power density. It is suitable for applications with high energy demand where energy storage needs to provide longterm electrical energy support. Deep discharge and high current charge and discharge can seriously shorten the battery life. On the other hand, SC is a power-type energy storage with high power density, but low energy density. Thus, it is suitable for applications with high power demand in a short time, such as improving power quality and providing fast power support. Combining a lithium battery and an SC as a hybrid energy storage system can take the advantages of the two, with improved utilization efficiency and reduced number of charges and discharges for extended service life.

According to the concept of droop control $[2,16]$, the droop characteristics of an SC charge/discharge powerDC bus voltage $\left(P_{\mathrm{SC}}-U_{\mathrm{dc}}\right)$, lithium battery charge/discharge power-SC voltage $\left(P_{B a t}-U_{\mathrm{SC}}\right)$ are shown in Fig. 4 , and their mathematical expressions are given as:

$$
\begin{aligned}
& P_{S C}=\left\{\begin{array}{c}
P_{S C \_d i s c \_ \text {Limit }}, U_{d c} \leq U_{d c \_l o w} \\
k_{1} U_{d c}+C_{1}, U_{d c \_l o w} \leq U_{d c} \leq U_{d c \_ \text {high }} \\
P_{S C_{-} \text {char_Limit }}, U_{d c} \geq U_{d c \_ \text {high }}
\end{array}\right. \\
& P_{\text {Bat }}=\left\{\begin{array}{c}
P_{\text {Bat_disc_Limit }}, U_{S C} \leq U_{S C \_ \text {low }} \\
k_{2} U_{S C}+C_{2}, U_{S C \_l o w} \leq U_{S C} \leq U_{S C \_ \text {high }} \\
P_{\text {Bat_char_Limit }}, U_{S C} \geq U_{S C \_ \text {high }}
\end{array}\right.
\end{aligned}
$$

where $\quad P_{\mathrm{SC}}, P_{\text {SC_disc_Limit }}, P_{\text {SC_char_Limit }} 、 P_{\text {Bat }}, P_{\text {Bat_di- }}$ sc_Limit and $P_{\text {Bat_char_Limit }}$ represent SC power, SC maximum generating power, $\mathrm{SC}$ maximum charging power, lithium battery power, lithium battery maximum discharge power, and lithium battery maximum charging power, respectively. $U_{\mathrm{dc}}, U_{\mathrm{dc} \_ \text {low }}, \mathrm{U}_{\mathrm{dc} \_ \text {high }}, U_{\mathrm{SC}}, U$ SC-low and $U_{\mathrm{SC} \_ \text {high }}$ represent $\mathrm{DC}$ bus voltage, DC bus voltage lower limit, DC bus voltage upper limit, SC voltage, SC voltage lower limit, and SC voltage upper limit,

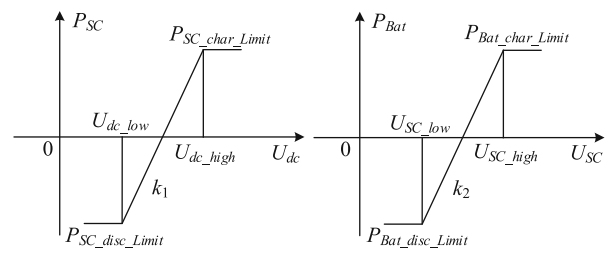

Fig. 4 Droop control characteristic curve of hybrid energy storage respectively. $k_{1}$ and $k_{2}$ represent the sagging coefficients of the sagging characteristic curves of $P_{\mathrm{SC}}-U_{\mathrm{dc}}$ and $P_{\mathrm{Bat}}{ }^{-}$ $U_{\mathrm{SC}}$, respectively. $\mathrm{C}_{1}, \mathrm{C}_{2}$ are constants representing the intercepts of the sagging characteristic curves of $P_{\mathrm{SC}}-U_{\mathrm{dc}}$ and $P_{\mathrm{Bat}}-U_{\mathrm{SC}}$, respectively.

From the hybrid energy storage sagging characteristic graph in Fig. 4, the hybrid energy storage converter control circuit is shown in Fig. 5. The lithium battery and the $\mathrm{SC}$ are connected in parallel to the DC bus through converters, and the charging and discharging power is adjusted according to the magnitude of their DC bus voltages.

\subsection{Grid-connected converter}

In order to ensure the stable transmission of electrical energy during the grid connection process, in this paper, the GCC uses power droop control in the on-grid mode. The droop characteristic of the grid-connected converter power-DC bus voltage $\left(P_{G C C}-U_{d c}\right)$ is shown in Fig. 6 and its mathematical expressions are given as:

$$
P_{G C C}=\left\{\begin{array}{c}
P_{G C C \_ \text {rect_Limit }}, U_{d c} \leq U_{d c \_l o w 2} \\
k_{3} U_{d c}+C_{3}, U_{d c \_l o w 2} \leq U_{d c} \leq U_{d c \_l o w 1} \\
0, U_{d c \_l o w 1} \leq U_{d c} \leq U_{d c \_h i g h 2} \\
k_{3} U_{d c}+C_{4}, U_{d c \_h i g h 2} \leq U_{d c} \leq U_{d c \_ \text {high } 1} \\
P_{G C C \_ \text {inv_Limit }}, U_{d c} \geq U_{d c \_h i g h 1}
\end{array}\right.
$$

where $P_{\mathrm{GCC}} 、 P_{\mathrm{GCC} \_ \text {rect_Limit }}$ and $P_{\mathrm{GCC} \_ \text {inv_Limit }}$ represent the converter power, maximum converter power in rectifier mode, and maximum converter power in inverter mode, respectively. $U_{\mathrm{dc} \_l o w 1}, U_{\mathrm{dc} \_ \text {low2 } 2}, U_{\mathrm{d}-}$ c_high1 $U_{\mathrm{dc} \_ \text {high2 }}$ represent the DC bus voltage lower limit 1, 2 and upper limit 1, 2, respectively. $\mathrm{k}_{3}$ represents the sag coefficient of the $P_{\mathrm{GCC}} U_{\mathrm{dc}}$ sag characteristic curve, while $C_{3}$ and $C_{4}$ are constants and

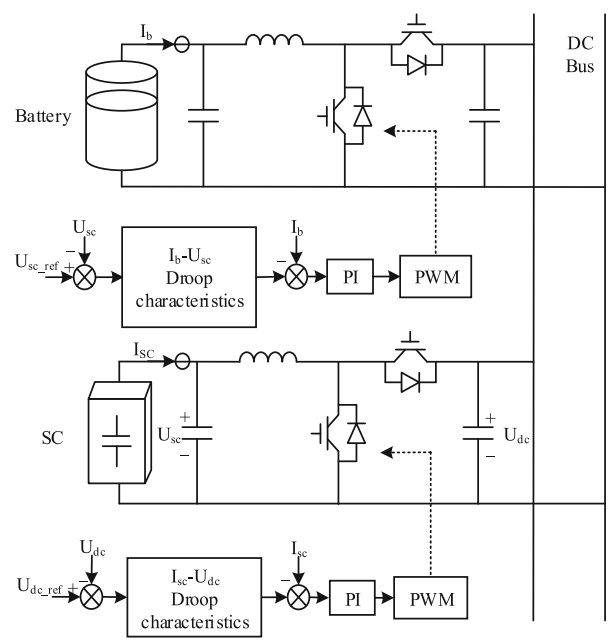

Fig. 5 Hybrid energy storage droop control strategy 


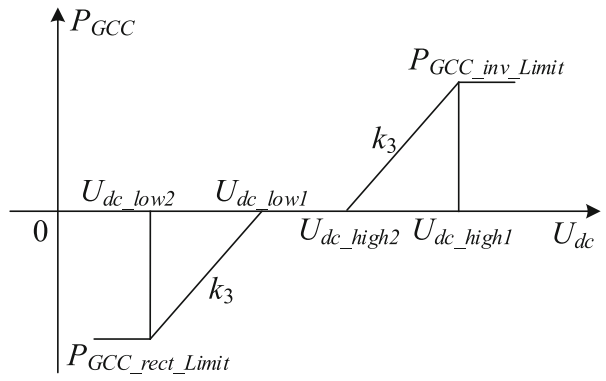

Fig. 6 Droop control characteristic curve of GCC

represent the intercepts of the $P_{\mathrm{GCC}}-U_{\mathrm{dc}}$ sagging characteristic curve, respectively.

According to the detected AC side current which serves as the feedback and control quantities, the control strategy of the GCC can be divided into "indirect current control" [18] and "DC current control" [35]. The indirect current control strategy does not need to detect the AC side current as feedback. The control principle is simple and reliable, but the AC side current dynamic response is slow so it can only be used in applications where fast system dynamic response is not required. Compared with indirect current control, DC current control introduces AC side current feedback, and the system's AC side current dynamic response speed is fast [44]. Therefore, this paper uses a vector decoupling direct current control strategy based on the $d q$ coordinate system, as shown in Fig. 7.

\section{Energy management control strategy for a household-level electric power router}

For the DC MG, since there is no need to consider reactive power, the DC bus voltage is the most important indicator and reflects the balance of system power [4]. Distributed power sources in the MG, random changes in load power, and power exchange with the external grid all have a certain effect on the bus voltage. By decoupling the distributed power, energy storage, load, and the exchange power of the MG and the distribution

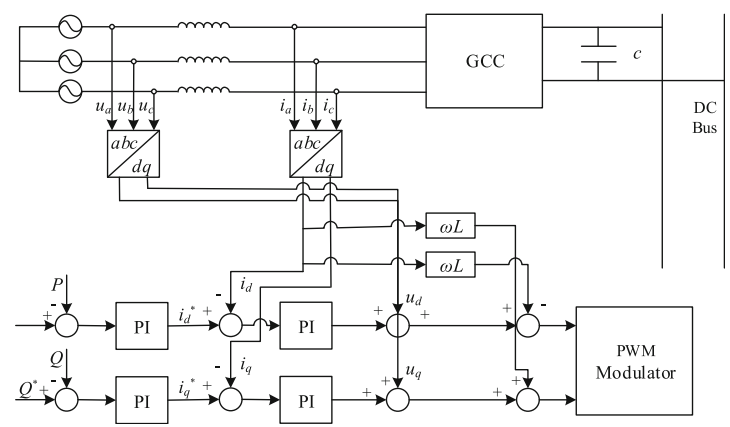

Fig. 7 Vector decoupling direct current control strategy based on dq coordinate system network, the DC bus equivalent circuit of the DC MG can be obtained [45].

According to the system power balance, the power of the $\mathrm{DC}$ bus equivalent capacitance $\mathrm{C}$ is:

$$
P_{C}=P_{P V}+P_{G}+P_{H E S}-P_{L}
$$

where $P_{C} 、 P_{P V} 、 P_{G} 、 P_{H E S}$ and $P_{L}$ represent the power of the DC bus equivalent capacitance, PV generation, grid, hybrid energy storage, and load, respectively.

The relationship between the DC bus voltage and DC bus equivalent capacitance power is:

$$
\begin{aligned}
& P_{\mathrm{C}}=U_{\mathrm{dc}} C \frac{d U_{\mathrm{dc}}}{d t} \\
& U_{\mathrm{dc}} \frac{d U_{\mathrm{dc}}}{d t}=\frac{1}{C}\left(P_{P V}+P_{G}+P_{H E S}-P_{L}\right)
\end{aligned}
$$

If $U_{d c}$ remains stable, i.e., $d U_{\mathrm{dc}} / d t=0$, there is:

$$
P_{P V}+P_{G}+P_{H E S}=P_{L}
$$

To ensure power balance the current of the mixed energy storage is:

$$
I_{H E S}=\frac{P_{H E S}}{U_{d c}}=\frac{P_{L}-P_{P V}-P_{G}}{U_{d c}}
$$

where $I_{H E S}$ represents the mixed energy storage current. As long as the energy storage system can provide enough current, the DC bus voltage can remain stable regardless of the changes in PV power and load. However, because of the limit on the current of the energy storage system, the DC bus voltage can fluctuate and thus other controls must be incorporated so the DC voltage can still be stabilized within a certain range.

Based on the characteristics of household-level electrical energy management and the requirements of DC MG control, this paper proposes a power control strategy for a household-level EPR, as shown in Fig. 8. Its flow chart is shown in Fig. 9. The system operation mode is divided into on-grid mode and off-grid mode, and the DC bus voltage is divided into three parts within the allowed variation range of $U_{d c_{-} \text {low }}, U_{d c_{-} \text {rate }}$ and $U_{d c \_n i g h}$. Thus the system is divided into six

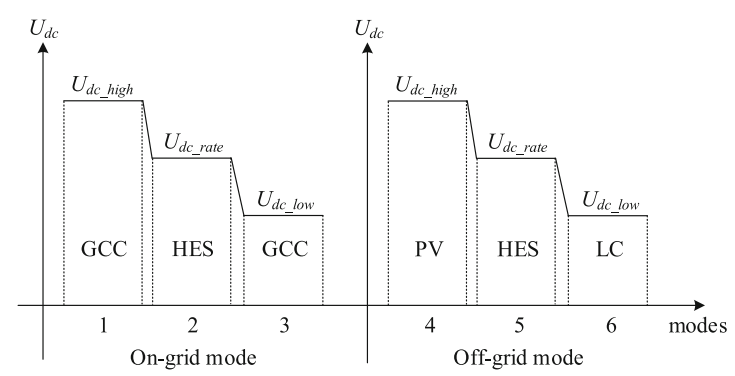

Fig. 8 Power control strategy for a household-level EPR 


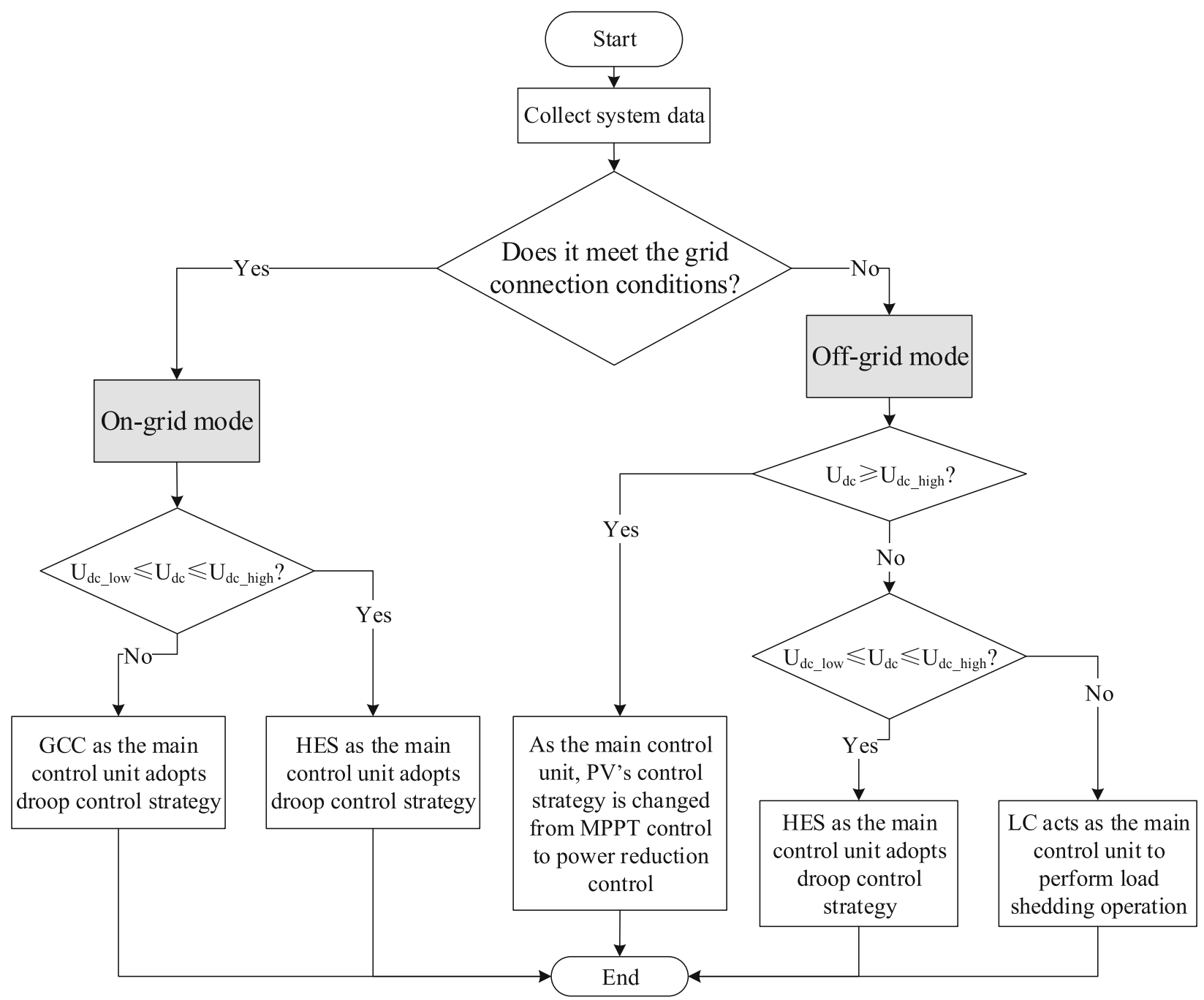

Fig. 9 Flow chart of Power control strategy for a household-level EPR

operational modes. In each mode of operation, a slack terminal is assigned to stabilize the bus voltage while the other distributed units provide power output. When the slack terminal cannot stabilize the bus voltage in each operational mode, the system enters other working areas.

(1) In the on-grid mode, PV always adopts the MPPT control strategy. When $U_{d c} \geq U_{d c_{-} \text {high }}$ or $U_{d c} \leq U_{d c_{-} \text {low }}$, GCC is used as the main control unit of the system, adopting the droop control strategy, and when $U_{d c_{\_} \text {low }} \leq$ $U_{d c} \leq U_{d c \_h i g h}$, HES is used as the main control unit, it adopts the HES droop control strategy.

(2) In off-grid mode, GCC is out of service. When $U_{d c} \geq U_{d c_{-} \text {high }}$, PV is converted from MPPT operation to power reduction control. When $U_{d c_{-} \text {low }} \leq U_{d c} \leq U_{d c_{-} \text {high, }}$ HES is used as the main control unit, adopting droop control, and when $U_{d c} \leq U_{d c \text { low }}$, system LC performs a load shedding operation to maintain bus voltage stability.

Table 1 summarises the different operational mode for each of the units during on-grid and off-grid operations. The switchover of the on/off-grid mode mainly depends on actual user needs and operating status (overhaul, fault) on the grid side. Regardless of the mode of operation, the system operating state is adjusted based on the DC bus voltage. In any operating state, at least one converter is used as a slack terminal to stabilize the DC bus voltage, while the other converters are used as power terminals to provide power to the system.

\subsection{On-grid mode}

In the on-grid mode, household-level electrical energy routing devices follow the principles of "spontaneous self-use, excess online access", and "time-sharing 
Table 1 Classification of each unit's operational states

\begin{tabular}{lll}
\hline Subunit & On-grid mode & Off-grid mode \\
\hline PV & MPPT & Power down control/MPPT \\
Battery & Droop control & Droop control \\
SC & Droop control & Droop control \\
GCC & Droop control & Standby \\
LC & load shedding & load shedding \\
\hline
\end{tabular}

electricity use, peak-valley arbitrage". The load preferentially uses the power generated by PV, followed by the grid. The GCC acts as a slack terminal to maintain the voltage stability of the DC bus, while to ensure the utilization efficiency of renewable energy, PV always use MPPT control to generate electricity. Any surplus electric energy from PV can be stored in energy storage batteries or integrated into the power grid for economic operation of the system.

\subsubsection{Scenario 1}

When the light conditions are good, the power generated by the PV is given priority to the user's load. The specific energy optimization management strategies are as follows:

(1) HES does not reach the maximum power of charge and discharge

(1) The power of PV is greater than the power required by the load.

The PV power generation is given priority to the load and the surplus power is used to charge the hybrid energy storage. The surplus PV power not being completely absorbed is then integrated into the grid. The energy flow diagram is shown in Fig. 10(a);

(2) The power of PV is less than the power required by the user load.

The power of PV is used to charge the battery while the user load is supplied by the grid. The energy flow diagram is shown in Fig. 10(b).

(2) HES reaches the maximum power of charge and discharge

(1) The power of PV is greater than the power required by the user load.

The power of PV is given priority to the load and the surplus power is transmitted to the grid. The energy flow diagram is shown in Fig. 10(c);

(2) The power of PV is less than the power required by the user load.

PV and the grid supply the load together, and the energy flow diagram is shown in Fig. 10(d).

\subsubsection{Scenario 2}

At night, the grid supplies power to the load, and the energy strategy is as follows:

(1) HES does not reach the maximum power of charge and discharge

The grid supplies power to the load and also charges the battery. The energy flow diagram is shown in Fig. 10(e);

(2) HES reaches the maximum power of charge and discharge

The grid supplies power to the load, and the energy flow diagram is shown in Fig. 10(f).

\subsection{Off-grid mode}

In addition to the planned off-grid, when the grid fails, the household-level electrical energy routing device automatically changes from the on-grid mode to the off-grid mode. In the off-grid mode, the load uses PV power generation first, followed by hybrid energy storage.

In the off-grid mode, the PV cell generates power under MPPT control. The hybrid energy storage unit becomes the slack terminal and the main control unit of the system. This is responsible for maintaining the stability of the bus voltage. If the remaining power reaches the regulation limit of the hybrid energy storage power, it switches from droop control to constant power charging and discharging according to the system state, and the PV cell will turn to constant voltage control. When the remaining power of the system is much smaller than the load, the LC performs a load shedding operation.

\subsubsection{Scenario 1}

3.3 The power of $\mathrm{PV}$ is greater than the power required by the user load

The EPR stores the surplus power in the energy storage unit, and the energy flow diagram is shown in Fig. 11(a); 


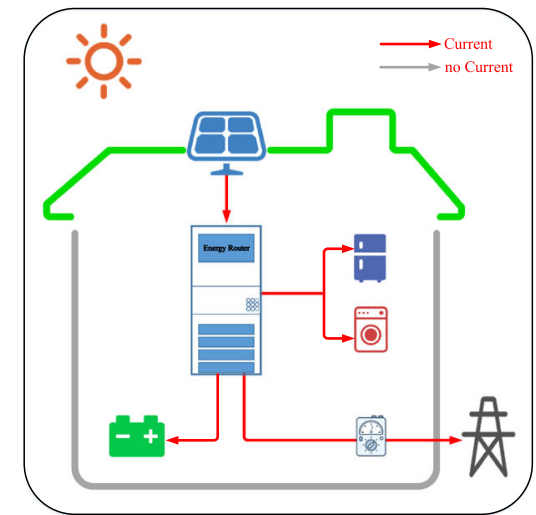

(a)

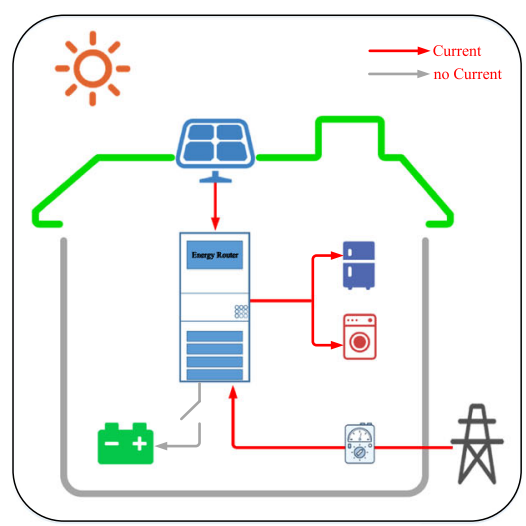

(d)

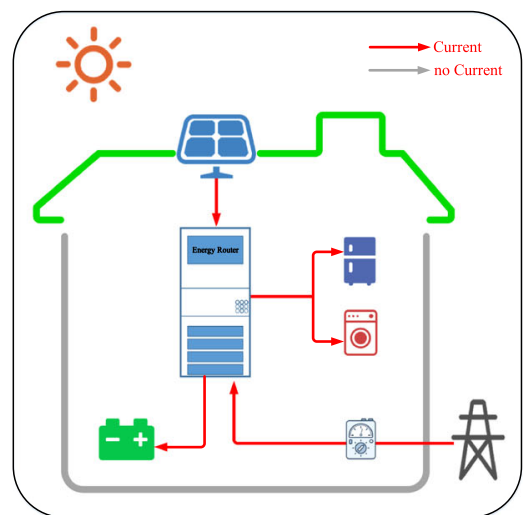

(b)

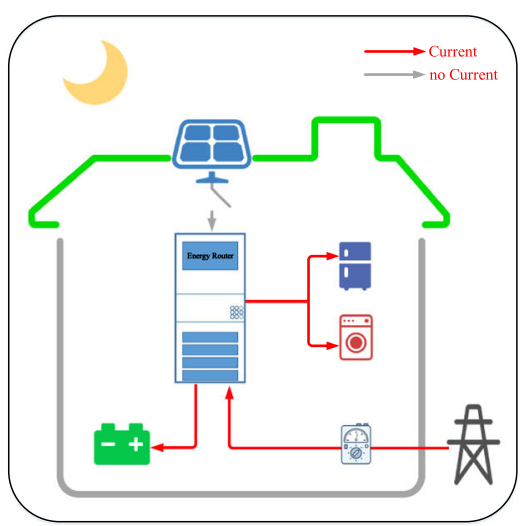

(e)

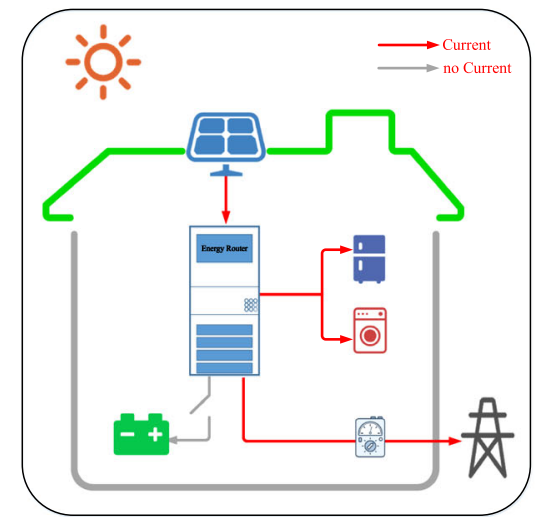

(c)

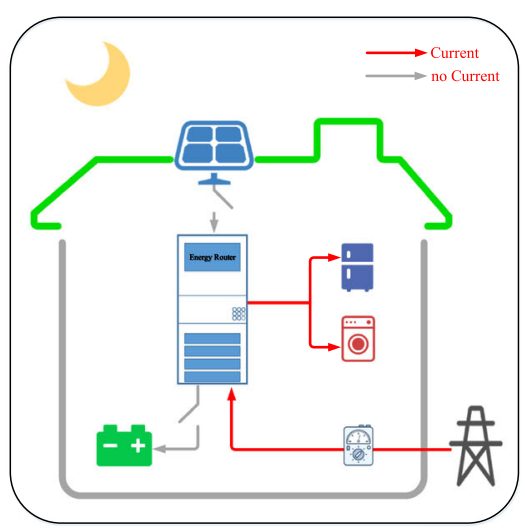

(f)

Fig. 10 Energy flow diagram in on-grid mode

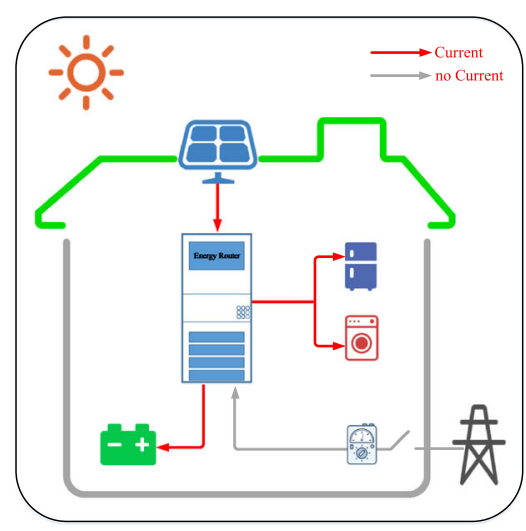

(a)

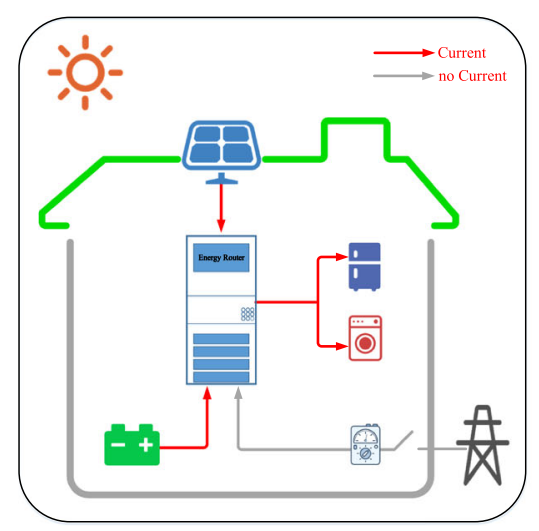

(b)

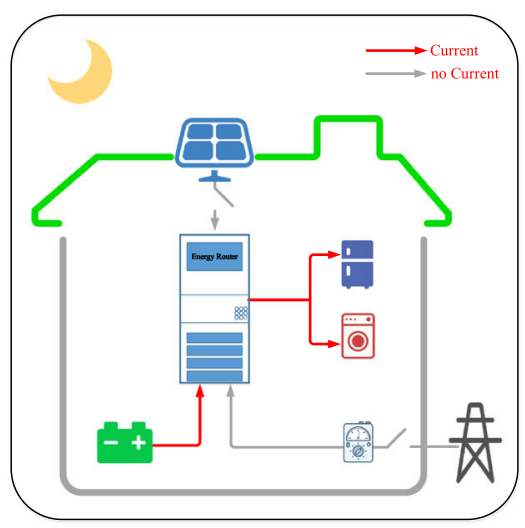

(c)

Fig. 11 Energy flow diagram in off-grid mode 
Table 2 Simulation parameters of household-level EPR

\begin{tabular}{lc}
\hline Simulation parameters & Rated value \\
\hline$U_{d c_{\text {rate }}}$ & {$[745,755] \mathrm{V}$} \\
$U_{\text {dc_high }}$ & {$[755,765] \mathrm{V}$} \\
$U_{\text {dc_rate }}$ & {$[735,745] \mathrm{V}$} \\
PV & $7.5 \mathrm{kWp}$ \\
SC & $300 \mathrm{~V}$ \\
Battery & $200 \mathrm{~V}-100 \mathrm{Ah}$ \\
GCC & $4 \mathrm{~kW}$ \\
DC Bus & $750 \mathrm{~V}(-20 \% \sim+5 \%)[15]$ \\
Loads & $1.6-5.0 \mathrm{~kW}$ \\
\hline
\end{tabular}
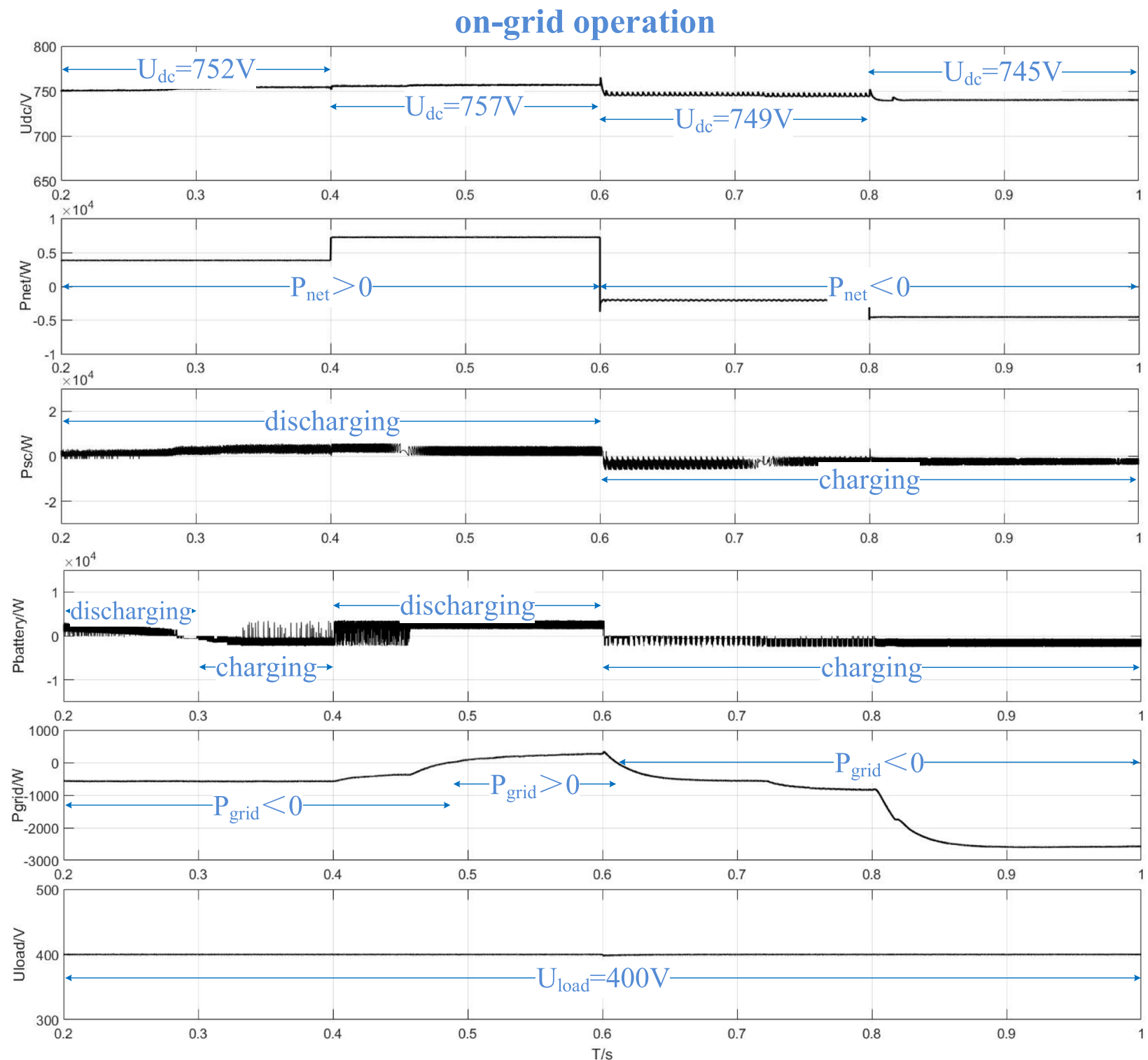

Fig. 12 Simulation results of on-grid operation 
3.4 The power of PV is less than the power required by the user load

The HES and PV supply the load together. The energy flow diagram is shown in Fig. 11(b).

\subsubsection{Scenario 2}

At night or in cloudy conditions, the PV has no output and the HES supplies power to the load. The energy flow diagram is shown in Fig. 11(c).

\section{Results and discussions}

To verify the power control strategy of the householdlevel EPR based on the HES droop control proposed in this paper, a household-based EPR model is built in PSCAD/EMTDC according to the topology shown in
Fig. 1. A preferred $750 \mathrm{~V}$ in the low-voltage power supply system is selected as the rated voltage of the MG DC bus [36]. The system simulation parameters are shown in Table 2. In Figs. 12, 13, 14, the net power $P_{\text {net }}$ equals $P_{\text {pv }}$ minus $P_{\text {load }}$.

\subsection{On-grid operational status}

The simulation results of on-grid operation are shown in Fig. 12, in which the PV always operates in MPPT mode. As seen, during $0.2 \sim 0.6 \mathrm{~s}$, the net power of the system is positive, so the DC bus voltage rises slightly. Specifically, during $0.2 \sim 0.4 \mathrm{~s}$, the DC bus voltage is maintained at $752 \mathrm{~V}$, the HES is used as a slack terminal, and the droop control method is used to charge and discharge to maintain the stability of the bus voltage. During $0.4 \sim$
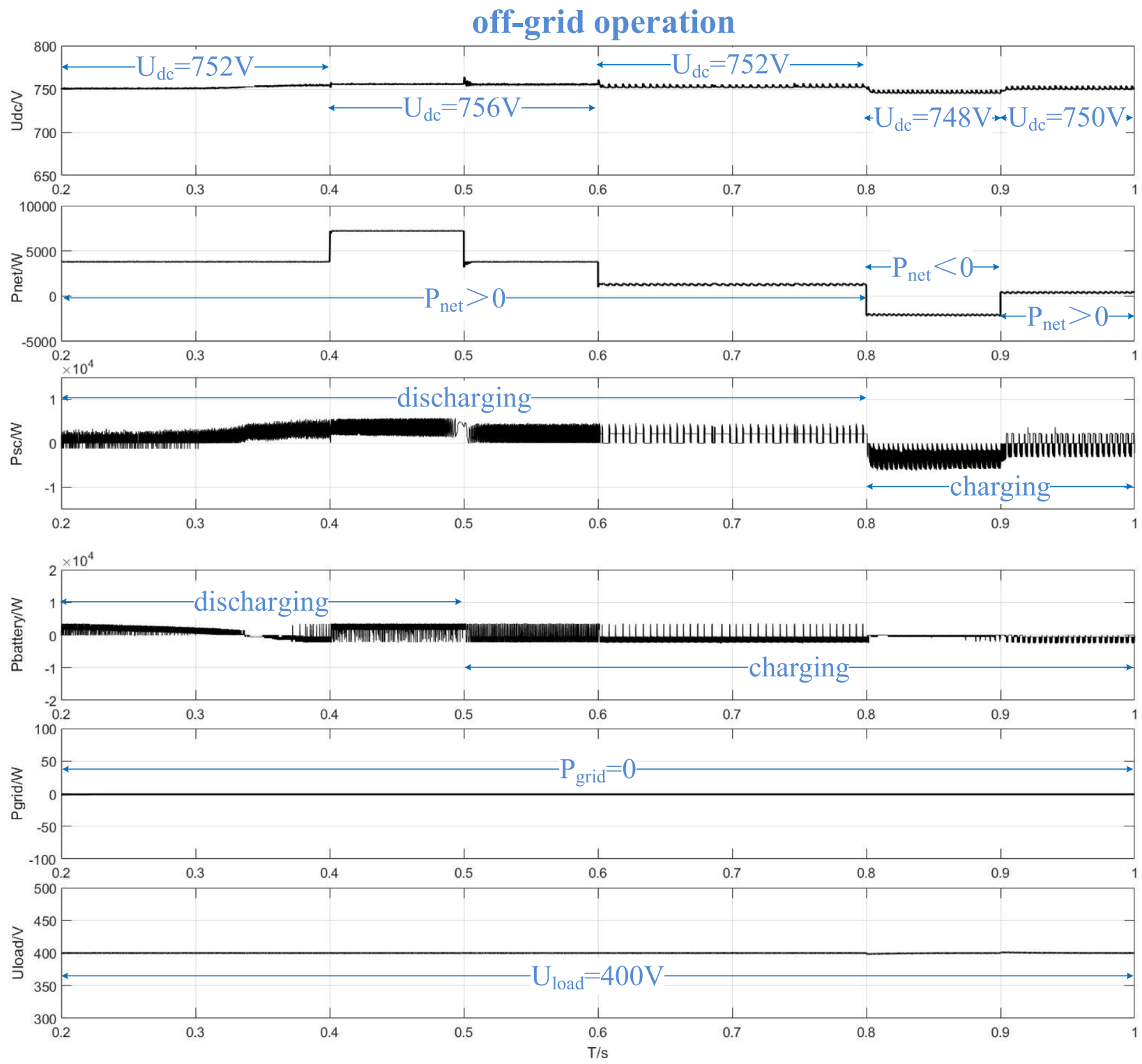

Fig. 13 Simulation results of off-grid operation 


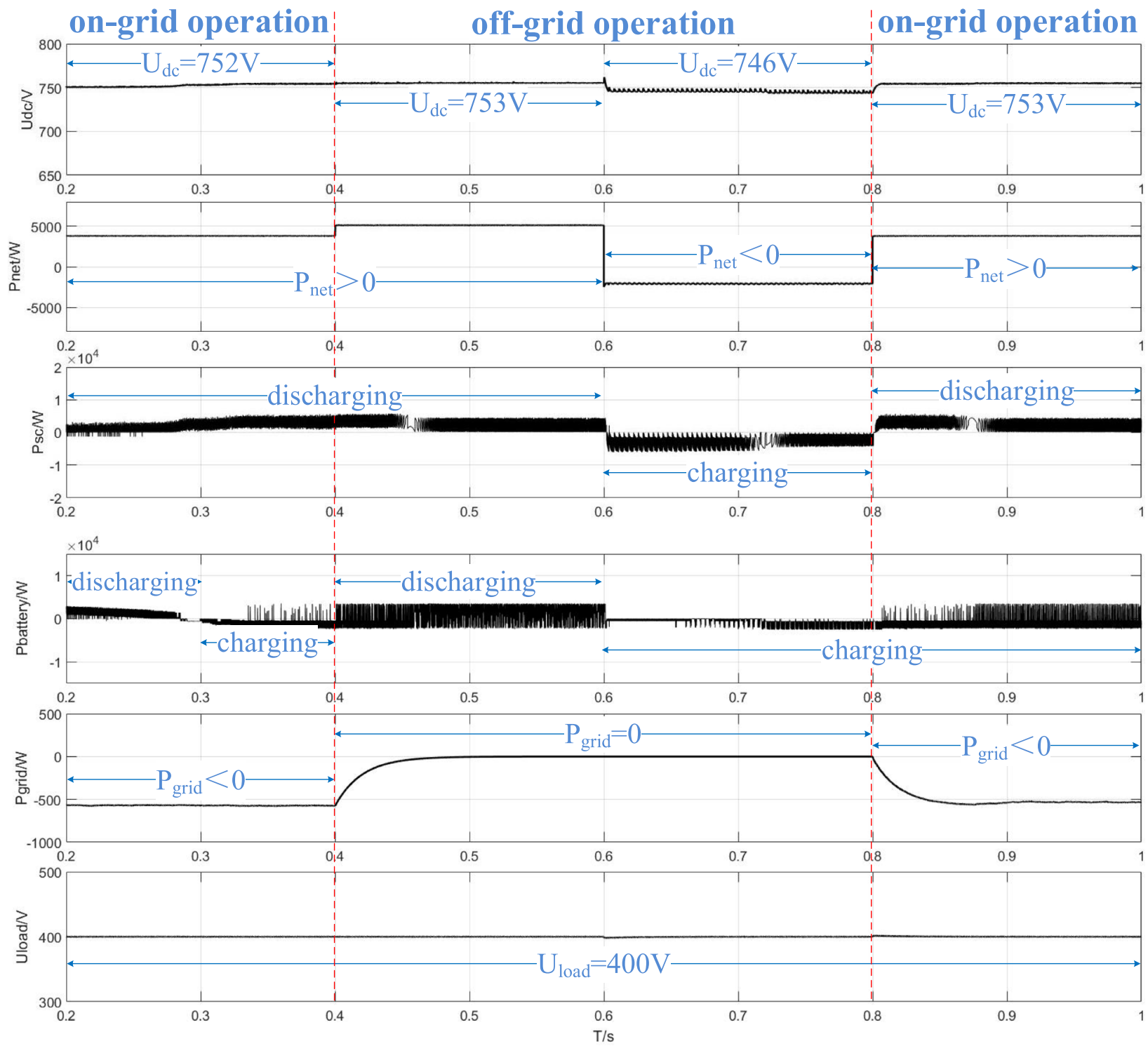

Fig. 14 Simulation results of on-grid to off-grid and then to on-grid switching

$0.6 \mathrm{~s}$, the DC bus voltage is maintained at $757 \mathrm{~V}$, while the GCC acts as the main control unit whose power transmission to the grid is controlled to maintain the stability of the DC bus voltage. During $0.6 \sim 1.0 \mathrm{~s}$, the net power of the system is negative and the DC bus voltage drops slightly. During $0.6 \sim 0.8 \mathrm{~s}$, the DC bus voltage is maintained at $749 \mathrm{~V}$ whereas during $0.8 \sim 1.0 \mathrm{~s}$, it drops to $745 \mathrm{~V}$. The HES and GCC serve as the slack terminal in the two stages, respectively.

\subsection{Off-grid operational status}

In off-grid mode, the GCC is not enabled and simulation results are shown in Fig. 13. As seen, during $0.2 \sim 0.4 \mathrm{~s}$, the DC bus voltage is maintained at $752 \mathrm{~V}$, the HES is used as a slack terminal, and the droop control method is used to charge and discharge to maintain bus voltage stability. During $0.4 \sim 0.6 \mathrm{~s}$, the DC bus voltage is maintained at $756 \mathrm{~V}$, while the PV becomes the main control unit of the system by adopting a reduced power with constant voltage control to stabilize the DC bus voltage. During $0.6 \sim 0.8 \mathrm{~s}$, the DC bus voltage is maintained at $752 \mathrm{~V}$. As $P_{\text {net }}$ is decreased, the PV is switched back to MPPT control and HES becomes the main control unit. During $0.8 \sim 1.0 \mathrm{~s}$, the DC bus voltage continues to decrease, and the load controller performs load shedding to maintain the bus voltage.

\subsection{On-grid and off-grid seamless switching}

In order to verify the feasibility and stability of the system and off-grid switching, the system operational mode 
is simulated and verified, as shown in Fig. 14. As seen, during $0.2 \sim 0.4 \mathrm{~s}$, the system operates in on-grid mode, and the DC bus voltage is maintained at $752 \mathrm{~V}$. During $0.4 \sim 0.8 \mathrm{~s}$, the system operates in off-grid mode. So as seen, during $0.4 \sim 0.6 \mathrm{~s}$, the DC bus voltage is maintained at $753 \mathrm{~V}$ and during $0.6 \sim 0.8 \mathrm{~s}, P_{\text {net }}$ is negative and the DC bus voltage drops to $746 \mathrm{~V}$. During $0.8 \sim 1.0 \mathrm{~s}$, the system goes back to on-grid operation, $P_{\text {net }}$ is positive and the DC bus voltage rises to $753 \mathrm{~V}$.

\section{Conclusions}

The rapid development of PV and other intermittent renewable energy power generation technologies requires power control from the user side to ensure system stability and supply security. Therefore, this paper proposes an energy power control strategy based on HES droop control for the household-level EPR and a user's actual operating scenario. The proposed strategy is verified through simulations. The simulation results show that:

(1) In on-grid mode, under the support of the grid, the system can better maintain DC bus voltage stability and achieve stable operation under severe operating conditions such as a rapid decrease of PV output power;

(2) In off-grid mode, the fluctuation of PV output has a great impact on the system DC bus voltage.

(3) (3) The DC bus voltage fluctuations are small during on and off-grid switching, and seamless switching is achieved. The types of user-side loads are increasingly diversified and intelligent. Thus how to classify and manage user-side loads will be the focus of future research.

\section{Abbreviations}

MG: Microgrid; PV: Photovoltaic; SC: Supercapacitors; EPR: Electric power router; LC: Load converter; HES: Hybrid energy storage; MPPT: Maximum Power Point Tracking; GCC: Grid-connected converter; I-V: Current-voltage; PV: Power-voltage

\section{Acknowledgments}

This work is supported by National Key R\&D Program of China (2018YFB0905000) and Science and Technology Project of State Grid Corporation of China (SGTJDKO0DWJS1800232).

\section{Authors' contributions}

K. Huang and Y. Li, the main authors of this study, their contributions included the model building, operation mode design and the paper writing. $X$. Zhang and L. Liu, they guided the study at all stage and improved the text. Y. Zhu and X. Meng, the supervisors of the study, they reviewed and improved the text. And Y. Zhu is the corresponding author. The authors read and approved the final manuscript.

\section{Funding}

National Key R\&D Program of China (2018YFB0905000).

Science and Technology Project of State Grid Corporation of China (SGTJDKO0DWJS1800232).

\section{Availability of data and materials}

All data generated or analyzed during this study are included in the published article (and its supplementary information files).

\section{Declarations}

\section{Competing interests}

The authors declare that they have no competing interests.

\section{Author details}

'NARI Technology Development Co., Ltd, No.19, Chengxin Avenue, Jiangning District, Nanjing City, Jiangsu Province, China. ${ }^{2}$ Nari Group Corporation/State Grid Electric Power Research Institute, No.19, Chengxin Avenue, Jiangning District, Nanjing City, Jiangsu Province, China. ${ }^{3}$ School of Physics, University of Oxford, Oxford OX13RH, UK. ${ }^{4}$ Key Laboratory of Smart Grid of Ministry of Education, Tianjin University, Tianjin 300072, China.

Received: 17 July 2020 Accepted: 9 March 2021

Published online: 06 April 2021

\section{References}

1. Bayati, M., Abedi, M., Gharehpetian, G. B., et al. (2019). Short-term interaction between electric vehicles and microgrid in decentralized vehicle-to-grid control methods []]. Protection and Control of Modern Power Systems, 4(1), $1-11$

2. Bo, W., Wenping, Q., Xiaoging, H., et al. (2015). Control strategy of hybrid energy storage systems in DC microgrid based on voltage droop method [J]. Power System Technology, 39(4), 892-898.

3. Chao, Z., \& Xiangning, H. (2006). Short-current combined with perturbation and observation maximum-power-point tracking method for photovoltaic power systems []]. Proceedings of the CSEE, 026(020), 98-102.

4. Chen, D., \& Xu, L. (2012). Autonomous DC voltage control of a DC microgrid with multiple slack terminals [J]. Power Systems IEEE Transactions on, 27(4), 1897-1905. https://doi.org/10.1109/TPWRS.2012.2189441.

5. Chen, H., Wang, X., Li, Z., et al. (2019). Distributed sensing and cooperative estimation/detection of ubiquitous power internet of things [J]. Protection and Control of Modern Power Systems, 4(1), 1-8.

6. Cheng, Y., \& Zhang, C. (2017). Configuration and operation combined optimization for EV battery swapping station considering PV consumption bundling [J]. Protection and Control of Modern Power Systems, 2(1), 26. https://doi.org/10.1186/s41601-017-0056-y.

7. China Electricity Council Standardization Management Center. China Electricity Council Standardization Management Center on the solicitation of the national standard "Energy Internet Part 5: Energy Router (Energy Router) Functional Specifications and Technical Requirements" (Draft for Comments) [N/OL], 2017-12-06. http://dls.cec.org.cn/yijianzhengqiu/2017-1206/175753.html. Accessed 28 May 2020.

8. Chuang, L., \& Yuemei, Z. (2017). Topological structure and control strategy of hybrid cascaded power electronic transformer [J]. Power System Technology, 2, 596-603.

9. Chunming, T., Siping, L., Fan, X., \& Zheng, L. (2018). Optimal control strategy of three-port DC energy router under TCM modulation [J]. Power System Technology, 42(8), 2503-2511.

10. Daozuo, J., \& Zheng, H. (2012). Current status and prospects of DC distribution network research [J]. Automation of Electric Power Systems, 8, 98-104.

11. Fei, W., Shijie, Y., Jianhui, S., et al. (2005). Research on photovoltaic gridconnected power system [J]. Transactions of China Electrotechnical Society, 020(005), 72-74,91

12. Femia, N., Petrone, G., Spagnuolo, G., \& Vitelli, M. (2005). Optimization of perturb and observe maximum power point tracking method [J]. IEEE Transactions on Power Electronics, 20(4), 963-973. https://doi.org/10.1109/ TPEL.2005.850975.

13. Feng, X. (2013). Research on modeling and control strategy of microgrid [D]. Nanjing University of Science \& Technology.

14. Gu, Y., Xiang, X., Li, W., \& He, X. (2014). Mode-adaptive decentralized control for renewable DC microgrid with enhanced reliability and flexibility [J]. IEEE Transactions on Power Electronics, 29(9), 5072-5080. https://doi.org/10.1109/ TPEL.2013.2294204.

15. Guideline for standard voltages of medium and low voltage DC distribution system: GB/T 35727-2017[S]. 2017.

16. Jihong, Z., Peihong, Y., Fei, Z., et al. (2018). Multi mode droop control strategy for hybrid energy storage of micro-grid [J]. Electrical and energy management technology, 000(001), 78-83. 
17. Komurcugil, H., \& Kukrer, O. (2006). A new control strategy for singlephase shunt active power filters using a Lyapunov function [J]. IEEE Transactions on Industrial Electronics, 53(1), 305-312. https://doi.org/10.11 09/TIE.2005.862218.

18. Kuihua, W., Yuling, L., Ping, L., et al. (2008). Current source PWM rectifier based on indirect current control [J]. Proceedings of the CSU-EPSA, 03, 66-69.

19. Mao, C., Wang, D., \& Shu, F. (2010). Electronic power transformer [M]. China Electric Power Press.

20. Mao, X., Falconers, S., \& Ayanna, R. (2010). Energy based control design for a solid state transformer [C]. In Proceedings of IEEE PES general meeting, (pp. 1-7).

21. Na, Z., Hui, Z., \& Xiaowen, X. (2012). DC microgrid coordinated control strategy research [J]. Journal of Xi'an University of Technology, 04, 47-52.

22. Qianchen, G., Gang, Y., \& Lidan, Z. (2019). Research status and prospects of electric energy router technology [J]. Electric Power Construction, 040(006), 105-113.

23. Renle, H., Tianjiao, P., Kewen, L., et al. (2015). Design of functional system and application scheme of urban energy internet [J]. Automation of Electric Power Systems, 39(9), 26-33.

24. Runruo, C., Wu, H., \& Yan, X. (2012). A three-port converter suitable for wide input voltage range [J]. Proceedings of the Chinese Society for Electrical Engineering, 32(27), 119-125.

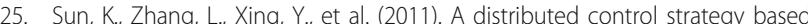
on DC bus signaling for modular photovoltaic generation systems with battery energy storage [J]. IEEE Transactions on Power Electronics, 26(10), 3032-3045. https://doi.org/10.1109/TPEL.2011.2127488.

26. Sundararajan, A., Khan, T., Moghadasi, A., et al. (2019). Survey on synchrophasor data quality and cybersecurity challenges, and evaluation of their interdependencies. Journal of Modern Power Systems and Clean Energy, 7(3), 449-467. https://doi.org/10.1007/s40565-018-0473-6.

27. Tao, Z., Fuxing, Z., \& Yan, Z. (2016). Study on energy management system of energy internet [J]. Power System Technology, v.40(386(01)), 156-165.

28. Tarnow, A., Haines, L., Barrera, J., \& Meyer, A. (2001). Design of a fuel cell hybrid electric heavy duty vehicle [C]. In Proceedings of the 18th international electric vehicle symposium (EVS.18)

29. Valderrama, G. E., Stankovic, A. M., \& Mattavelli, P. (2001). Dissipativity-based adaptive and robust control of UPS in unbalanced operation [J]. Power Electronics IEEE Transactions on, 18(4), 1056-1062.

30. Wang, D., Tian, J., Mao, C., Lu, J., Duan, Y., Qiu, J., \& Cai, H. (2016). A 10. kV/400.V 500.kVA electronic power transformer [J]. IEEE Transactions on Industrial Electronics, 63(11), 6653-6663. https://doi.org/10.1109/TIE.2016.2 586440.

31. Wang, T., Xu, J., Qingzhu, S., et al. (2020). Research on non-scheduled islanding supplied by photovoltaic power generations [J]. Power System Protection and Control, 48(5), 173-180.

32. Wanxing, S., Wu, M., Yu, J., et al. (2019). Key technologies and engineering practice of distributed renewable energy power generation cluster integration and absorption [J]. Proceedings of the Chinese Society of Electrical Engineering, 39(8), 2175-2186.

33. Wu, L., Zhengming, Z., Jianzheng, L., et al. (2006). Implementation of a single-stage three-phase grid-connected photovoltaic system with reactive power compensation [J]. Transactions of China Electrotechnical Society, $021(001), 28-32$

34. Wuhua, I., Yunjie, G. U., Yuxiang, W., et al. (2015). Control architecture and hierarchy division for renewable energy DC microgrids [J]. Automation of Electric Power Systems.

35. Xiaojun, Z. (2010). The research on three phase high power PWM rectifier system [D]. Harbin Engineering University.

36. Xisheng, T. (2020). Interpretation of GB/T 35727-2017 guideline for standard voltages of medium and low voltage DC distribution system [J]. Automation of Electric Power Systems, 44(1), 23-28.

37. Yao, Z., \& Xiao, L. (2013). Control of single. Phase grid. Connected inverters with nonlinear loads [J]. IEEE Transactions on Industrial Electronics, 60(4), 1384-1389.

38. Yongjun, Z., Siheng, Z., Siliang, L., \& Yingqi, Y. (2020). Dual planning of a distribution transformer considering the impact of distributed photovoltaics and energy storage access [J]. Power System Protection and Control, 48(24), 9-15.

39. Zhang, J., Wang, W., \& Bhattacharya, S. (2012). Architecture of solid state transformer. Based energy router and models of energy traffic [C]. In Innovative smart grid technologies. IEEE.
40. Zhang, L., Samson Shenglong, Y. U., Fernando, T., et al. (2019). An online maximum power point capturing technique for high-efficiency power generation of solar photovoltaic systems [J]. Journal of Modern Power Systems and Clean Energy, 7(2), 357-368.

41. Zhen, W. (2014). Research on key technologies of distributed energy storage system [D]. Tianjin University.

42. Zhenming, Z., Gaohui, F., Liqiang, Y., et al. (2017). The development and key Technologies of Electric Energy Router [J]. Proceedings of the CSEE, 037(013), 3823-3834.

43. Zhenya, L. (2015). Global energy internet [M]. China Electric Power Press.

44. Zhongjiu, Z. (2011). Research on control strategies and application of threephase voltage source PWM rectifier [D]. Dalian University of Technology.

45. Zhongtian, Z. (2018). Research on bus voltage control technology for DC microgrid [D]. Shandong University of Technology.

46. Zihu, Z. (2013). Research on four-port converter and its control strategy [D]. Nanjing University of Aeronautics and Astronautics.

\section{Submit your manuscript to a SpringerOpen ${ }^{\circ}$ journal and benefit from:}

- Convenient online submission

- Rigorous peer review

- Open access: articles freely available online

- High visibility within the field

- Retaining the copyright to your article

Submit your next manuscript at $>$ springeropen.com 